\title{
EFEKTIVITAS PAKET PELAYANAN MINIMAL TERHADAP KEMAMPUAN PEREMPUAN MENOPAUSE DALAM MENGATASI PERMASALAHAN FISIK, SEKSUAL DAN PSIKOLOGIS DI WILAYAH KOTA TANGERANG TAHUN 2018
}

\author{
Azizah Al Asri' ${ }^{1}$, Irna Nursanti ${ }^{2}$, Toha Muhaimin ${ }^{3}$ \\ Program Magister Keperawatan Fakultas Ilmu Keperawatan \\ Universitas Muhammadiyah Jakarta \\ Email : azizahnainar@gmail.com
}

\begin{abstract}
ABSTRAK
Menopause merupakan berhentinya siklus haid akibat dari hilangnya efektifitas folikel ovarium dalam memproduksi hormon estrogen, terjadi 12 bulan berturutturut tidak menstruasi . Hasil observasi pada 132 orang perempuan menopause di wilayah Kota Tangerang terdapat usia penduduk yang mengalami permasalahan rata-rata berusia 45-60 tahun. Tujuan : Untuk mengetahui efektifitas "Paket Pelayanan Minimal" terhadap kemampuan perempuan menopause dalam mengatasi permasalahan fisik, seksual dan psikologis. Penelitian ini menggunakan pendekatan kuantitatif dengan metode penelitian menggunakan metode quasi Eksperimental dan desain penelitian one group pre and post test design. Pengukuran data kuantitatif dilakukan sebelum (pre test) dan sesudah (post test) intervensi dengan menggunakan instrument berupa kuisioner dan booklet. Sampel dalam penelitian ini merupakan perempuan menopause usia 45-60 tahun di wilayah Kota Tangerang, dengan jumlah total sampel 132 responden, yaitu 132 responden pada satu kelompok Pre test dan post test dengan menggunakan teknik purposive sampling. Hasil penelitian didapatkan bahwa ada perbedaan yang signifikan sebelum dan sesudah dilakukan intervensi didapatkan nilai $\mathrm{p}$ value yang diperoleh pada permasalahan fisik 34,70 dengan SD 16,272, permasalahan seksual 24,05 dengan SD 5,235 dan permasalahan psikologis 12,66 dengan SD 3,932. Kesimpulan : Paket Pelayanan Minimal dapat dijadikan acuan dalam meningkatkan derajat kesehatan perempuan menopause.
\end{abstract}

Kata kunci : Menopause, Permasalahan Fisik, Seksual dan Psikologis

\begin{abstract}
Background: Menopause is the cessation of the menstrual cycle due to the loss of effectiveness of the ovarian follicles in producing estrogen, there are 12 consecutive months not menstruating. Observations on 132 postmenopausal women in the Tangerang city area have an age of population experiencing problems on average aged 45-60 years. Objective: To determine the effectiveness of the "Minimum Service Package" on the ability of menopausal women to overcome physical, sexual and psychological problems in the Tangerang city area in 2018. Method: This study used a quantitative approach with research methods by quasi experimental method with one group research design pre and post test design. Quantitative data measurement had done before (pre test) and after (post test) intervention using instruments in the form of questionnaires and booklets. The sample in this study
\end{abstract}


were menopausal women aged 45-60 years in the city of Tangerang, with a total sample of 132 respondents, there are 132 respondents in one group of Pre test and post test using purposive sampling technique. Results: The results showed that there were significant differences before and after the intervention with $p$ value obtained in physical problems 34.70 with SD 16.272, sexual problems 24.05 with SD 5.235 and psychological problems 12.66 with SD 3.932. Conclusion: Minimum Service Package can be used as a reference to improve the health status of menopausal women.

Keywords : Menopause, Physical, Sexual and Psychological Problems

\section{PENDAHULUAN}

Menopause adalah suatu waktu dalam kehidupan seorang perempuan ketika berhenti haid atau mentsruasi. Hal ini biasanya terjadi secara alami setelah usia 45 tahun (Jafari dkk, 2014). Menurut (Noroozi dkk, 2013) menyatakan bahwa rata-rata usia menopause adalah 51 tahun (dari 47-53 tahun).

Berdasarkan data World Health Organization (WHO) tahun 2014, pada tahun 2030 jumlah perempuan di seluruh dunia diperkirakan mencapai 1,2 milyar orang. Sedangkan di Indonesia pada tahun 2025 diperkirakan akan ada 60 juta perempuan menopause pada tahun $2016 \mathrm{di}$ Indonesia baru mencapai 14 juta perempuan menopause atau $7,4 \%$ dari total populasi yang ada.

Berdasarkan data Survei Demografi Kesehatan Indonesia (SDKI) tahun 2012, jumlah perempuan menopause sebanyak 25,4 juta jiwa dan diperkirakan pada tahun 2020 perempuan menopause dengan usia rata-rata 49 tahun sebanyak 30,3 juta jiwa. Pada tahun 2013, jumlah perempuan didunia yang memasuki menopause diperkirakan mencapai 1,2 milyar orang. Saat ini di Indonesia baru mencapai 14 juta perempuan menopause.

Namun menurut proyeksi penduduk Indonesia tahun 2000-2013 oleh badan statistik, jumlah penduduk perempuan diusia 50 tahun adalah 16,9 juta orang. Bahkan pada tahun 2015 diperkirakan akan ada 60 juta perempuan menopause.
Sindrom menopause oleh banyak perempuan hampir seluruh dunia sekitar $70-80 \%$ perempuan Eropa, 60\% perempuan di Amerika, 57\% perempuan di Malaysia, $18 \%$ perempuan di Cina, $10 \%$ wanita di Jepang, dan di Indonesia diperkirakan $5 \%$ dari jumlah penduduk. (Hawari, 2013)

Berdasarkan data dari LKPJ (Laporan Keterangan Pertanggung Jawaban) Kota Tangerang Tahun 2013, bahwa Angka Harapan Hidup (AHH) di Kota Tangerang pada tahun 2013 mencapai 50-69 tahun, artinya rata-rata umur yang dijalani oleh penduduk Kota Tangerang mencapai umur 50-69 tahun pada pada tahun 2012, dalam situasi mortalitas yang berlaku di lingkungan Kota Tangerang. Angka harapan hidup ini terus meningkat sejak tahun 2011 yakni 41- 68 tahun dan tahun 2012 yakni 44-68 tahun. Rencana Kerja Pemerintah Daerah (RKPD) Kota Tangerang Tahun 2015 tersebut menyiratkan optimisme bahwa pada tahuntahun mendatang AHH masih bisa meningkat. Meningkatnya UHH terutama pada perempuan, mendorong kebijakan terhadap penduduk usia tua, bertambahnya jumlah penduduk tua dapat dimaknai sebagai meningkatnya tingkat kesejahteraan, meningkatnya kondisi kesehatan tetapi juga dapat dimaknai sebagai beban karena kelompok usia tua ini sudah tidak produktif lagi (Kementerian Kesehatan RI, 2015).

Beberapa penelitian yang berhubungan dengan penelitian yang 
dilakukan oleh Calapi (2014) yang mengambarkan responden yang telah menopause mengalami perubahan pada fisik, perilaku seksual, dan psikologis pada usia 45-50 tahun. Beberapa penelitian, Ching_Hui Chen dkk (2012) adanya gangguan hasrat seksual hypoactive, gangguan rangsangan seksual, gangguan orgasme mengacu pada ketidakmampuan untuk mencapainya orgasme, kelainan nyeri seksual mengacu pada nyeri pada panggul atau vagina selama tahap tahap seksual normal, termasuk keinginan, gairah, atau orgasme.

Upaya yang dilakukan untuk mengatasi permasalahan fisik, sexual dan psikologis adalah dengan memberikan paket pelayanan minimal, dimana dalam paket tersebut mencakup pemberian pengetahuan atau pemahaman mengenai cara mengatasi permasalahan fisik, seksual dan psikologis. Perubahan sikap pada menopause dengan cara memberikan pengetahuan untuk meningkatkan ketrampilan dalam merawat diri.

\section{METODE PENELITIAN}

Penelitian ini adalah quasi Eksperimental dengan desain penelitian one group pre and post test design dengan metode kuantitatif. Pengukuran data kuantitatif sebelum (pre test) dan sesudah (post test) intervensi dilakukan dengan menggunakan kuisioner. Sebanyak 132 responden ikut serta dalam penelitian ini. Kemudian dibagi menjadi dua kelompok intervensi yaitu sebelum diberikan intervensi dan sesudah diberikan intervensi dengan responden yang sama.

Data diolah menggunakan komputer. Kaji etik dilakukan oleh Komite Etik Riset Fakultas Ilmu Keperawatan Universitas Muhammadiyah Jakarta.

\section{HASIL}

Tabel 1.

Karakteristik responden di 15 Puskesmas Kota Tangerang, 2018

$(n=132)$

\begin{tabular}{llcc}
\hline \multirow{2}{*}{ Variabel } & Deskriptif & \multicolumn{2}{c}{$\begin{array}{c}\text { Intervensi } \\
\text { n= 132 }\end{array}$} \\
\cline { 3 - 4 } Usia & Mean & F & \multicolumn{2}{c}{ \% } \\
& Median & \multicolumn{2}{c}{47} \\
& Std. Deviasi & \multicolumn{2}{c}{2,550} \\
& Min - Maks & \multicolumn{2}{c}{$41-50$} \\
\hline Pendidikan & Tinggi & 30 & 27,7 \\
\multirow{3}{*}{ Pekerjaan } & Rendah & 102 & 77,3 \\
\multirow{2}{*}{ Agama } & Tidak Bekerja & 45 & 34,1 \\
& Bekerja & 87 & 65,9 \\
& Non Muslim & 35 & 26,5 \\
& Muslim & 97 & 73,5 \\
\hline
\end{tabular}

Berdasarkan tabel menunjukkan bahwa dari 132 responden dapat dilihat sebagian besar responden berumur $>45$ tahun
(72,0\%), berpendidikan rendah $(77,3 \%)$, status pekerjaan $(65,9 \%)$, dan beragama Islam $(73,5 \%)$. 


\section{Tabel 2}

Gambaran Efek Pemberian Paket Pelayanan Minimal Terhadap Kemampuan Mengatasi Permasalahan Fisik, Seksual, dan Psikologis

\begin{tabular}{llccccc}
\hline \multicolumn{1}{c}{ Variabel } & Kelompok & Mean & SD & $\begin{array}{c}\text { Min- } \\
\text { maks }\end{array}$ & 95\% CI & P value \\
\hline Permasalahan & Sebelum & 39,32 & 11,065 & $10-70$ & $37,41-41,22$ & 0,000 \\
Fisik & Sesudah & 74,02 & 10,903 & $60-90$ & $72,14-75,89$ & 0,000 \\
Permasalahan & Sebelum & 29,02 & 2,404 & $25-34$ & $28,61-29,44$ & 0,000 \\
Seksual & Sesudah & 53,08 & 1,711 & $5-13$ & $52,27-53,88$ & 0,000 \\
Permasalahan & Sebelum & 10,06 & 1,711 & $5-15$ & $9,77-10,36$ & 0,000 \\
Psikologis & Sesudah & 22,72 & 3,548 & $17-28$ & $22,11-23,33$ & 0,000 \\
\hline
\end{tabular}

Berdasarkan tabel 2 didapatkan ratarata kemampuan mengatasi permasalahan fisik sebelum intervensi sebesar 39,32 (SD $=11,065)$, sedangkan kemampuan mengatasi permasalahan fisik sesudah intervensi sebesar 74,02 $(\mathrm{SD}=10,903)$ dengan nilai terendah 60 dan tertinggi 90 . Dari kemampuan masalah lain, didapatkan rata-rata kemampuan mengatasi permasalahan seksual sebelum intervensi sebesar 29,02 ( $\mathrm{SD}=2,404)$ dengan nilai terendah 25 dan tertinggi 34, sedangkan rata-rata kemampuan mengatasi permasalahan seksual sesudah intervensi 53,08 $(\mathrm{SD}=1,711)$ dengan nilai terendah 5 dan tertinggi 13 dan rata-rata kemampuan mengatasi permasalahan psikologis sebelum intervensi sebesar $10,06(\mathrm{SD}=1,711)$ dengan nilai terendah 5 dan tertinggi 15 , sedangkan rata-rata kemampuan mengatasi permasalahan psikologis sesudah intervensi 22,72 (SD = 3,548) dengan nilai terendah 17 dan tertinggi 28 .

Tabel 3

Distribusi Rata-Rata Efektifitas Paket Pelayanan Minimal

Dalam Mengatasi Permasalahan Fisik, Seksual dan Psikologis di wilayah Kota Tangerang $(N=51)$

\begin{tabular}{|c|c|c|c|c|c|}
\hline Variabel & $\mathbf{N}$ & Mean & $S D$ & p-value & CI;95\% \\
\hline $\begin{array}{l}\text { Mengatasi } \\
\text { permasalahan } \\
\text { Fisik } \\
\text { Sebelum } \\
\text { Sesudah }\end{array}$ & $\begin{array}{l}132 \\
132\end{array}$ & 34,70 & 16,272 & 0,000 & $-37,499--31,895$ \\
\hline $\begin{array}{l}\text { Mengatasi } \\
\text { permasalahan } \\
\text { Seksual } \\
\text { Sebelum } \\
\text { Sesudah }\end{array}$ & $\begin{array}{l}132 \\
132\end{array}$ & 24,05 & 5,235 & 0,000 & $-23,152--52,785$ \\
\hline $\begin{array}{l}\text { Mengatasi } \\
\text { permasalahan } \\
\text { Psikologis } \\
\text { Sebelum } \\
\text { Sesudah }\end{array}$ & $\begin{array}{l}132 \\
132 \\
\end{array}$ & 12,66 & 3,932 & 0,000 & $-13,336--11,982$ \\
\hline
\end{tabular}

Berdasarkan tabel 4 menunjukkan bahwa pada permasalahan fisik sebelum dan sesudah intervensi didapatkan rata-rata 34,70 dengan standar deviasi 16,272. Hasil 
uji statistik didapatkan nilai p value 0.000 , maka dapat disimpulkan ada perbedaan signifikan antara fisik sebelum dan sesudah intervensi. Untuk faktor seksual, didapatkan nilai rata-rata sebelum dan sesudah intervensi 24,05 dengan standar deviasi 5,235 . Hasil uji statistik didapatkan nilai $\mathrm{p}$ value 0.000 , maka dapat disimpulkan ada perbedaan signifikan antara seksual sebelum dan sesudah intervensi. Sedangkan untuk faktor psikologis didapatkan rata-rata sebelum dan sesudah intervensi 12,66 dengan standar deviasi 3,932. Hasil uji statistik didapatkan nilai $\mathrm{p}$ value 0.000 , maka dapat disimpulkan ada perbedaan signifikan antara psikologis sebelum dan sesudah intervensi.

\section{PEMBAHASAN}

Hasil penelitian menunjukkan bahwa rata-rata usia responden sebelum diberikan dan sesudah diberikan paket pelayanan minimal pada menopause (pre dan post) berada pada rentang usia diatas usia 45 tahun keatas. Usia sangat mempengaruhi terjadinya menopause pada wanita. Namun ada juga yang menyatakan bahwa rata-rata usia menopause adalah 51 tahun(dari 47-53 tahun) (Noroozi dkk, 2013).

Hasil penelitian menunjukkan bahwa rata-rata perempuan menopause sebagian besar berpendidikan SMP. Secara umum pendidikan mempengaruhi kemampuan seseorang dalam menerima dan memahami informasi kondisi dan lingkungannya, sehingga mempengaruhi cara pandang dan pemilihan koping dalam menyelesaikan masalah. Pendidikan menurut Azwar (2008) bahwa pembentukan sikap terutama terjadi karena pendidikan atau pelatihan disamping adanya pengalaman, pengaruh, kebudayaan, media massa, dan emosional seseorang. sebagian besar perempuan menopause bekerja, hal ini dapat diartikan bahwa aktivitas perempuan menopause banyak berada diluar rumah atau bekerja. Sarafino (dalam Rohmawati 2004) menyebutkan tiga sumber stres yaitu diri sendiri, keluarga, komunitas dan lingkungan bahwa ibu bekerja memiliki sumber stres lebih banyak dan memiliki kerentanan stres lebih besar dibandingkan ibu tidak bekerja. Penelitian yang dilakukan oleh Apreviadizy (2014) menjelaskankan bahwa stres banyak dialami oleh ibu bekerja dibandingkan dengan ibu tidak bekerja dan penelitian yang dilakukan oleh Srirejeki (2010) terdapat hubungan antara semua karakteristik (usia, tingkat pendidikan, status pekerjaan) dengan sikap seksual wanita menopause. Terdapat hubungan antara persepsi fisik, psikis dengan sikap seksual wanita menopause. Status pekerjaan merupakan variabel yang paling berhubungan dengan sikap seksual wanita menopause.

Hasil penelitian menunjukkan bahwa pada fisik sebelum dan sesudah intervensi. Hasil uji statistik dapat disimpulkan ada perbedaan signifikan antara fisik sebelum dan sesudah intervensi. Untuk faktor seksual, didapatkan rata-rata sebelum dan sesudah intervensi dapat disimpulkan ada perbedaan signifikan antara seksual sebelum dan sesudah intervensi. Sedangkan untuk faktor psikologis didapatkan rata-rata sebelum dan sesudah intervensi, maka dapat disimpulkan ada perbedaan signifikan antara psikologis sebelum dan sesudah intervensi.

Hasil penelitian menunjukkan terjadi peningkatan baik pada permasalahan fisik nilai rata-rata $(74,04)$, pada permasalahan seksual $(53,08)$ dan permasalahan psikologis $(22,72)$ sesudah dilakukan intervensi pemberian "paket pelayanan minimal" terhadap peningkatan kemampuan dalam mengatasi permasalahan fisik, seksual dan psikologis pada menopause.

\section{KETERBATASAN PENELITIAN}

Beberapa keterbatasan penelitian yang ditemui pada saat penelitian berlangsung yaitu : pengisian kuisioner tidak diketahui seberapa jujur responden dalam melakukan pengisian kuisioner yang diberikan. Idealnya tehnik yang dilakukan melalui penelitian mix method (kolaborasi penelitian 
kuantitatif dan kualitatif). Serta beban kerja petugas kesehatan sangat banyak, sehingga kualitas pemberian paket pelayanan minimal tidak efektif.

\section{KESIMPULAN}

Hasil analisa univariat diketahui didapatkan pada responden usia responden sebelum diberikan dan sesudah diberikan paket pelayanan minimal pada menopause (pre dan post) berada pada rentang usia diatas usia 45 tahun keatas, berpendidikan rendah $(77,3 \%)$, memiliki pekerjaan $(65,9 \%)$ dan beragama islam $(73,5 \%)$. Hasil penelitian menunjukkan bahwa pada fisik

\section{DAFTAR PUSTAKA}

Admin. (2005). Terjadi Pengeseran Umur Menopause. www.mkia-kr.ugm.ac.id

Aina Safitri. (2009). Beberapa faktor-faktor yang mempengaruhi Menopause pada wanita dikelurahan Titi Papan Kota Medan:

http://repository.usu.ac.id/handle/1234 56789/14625

Aini, F (2010). Pengaruh Pendidikan Kesehatan Reproduksi Remaja Melalui Media Booklet Terhadap Perubahan Pengetahuan dan Santri tentang Kesehatan Reproduksi Di Pesantren Darul Hikmah Dan Ta'dib Al Syakirin Di Kota Medan: FKM USU

Alligood, MR \& Tomey AN. (2014). Nursing Theoritist and their work, sixth. Edition, St. Louis Mosby

Alwisol. (2004). Psikologi Kepribadian. Malang : Universitas Muhammadiyah Malang

Andira, D. (2010). Seluk Beluk Kesehatan Reproduksi Wanita.Yogyakarta: A.Plus Book

Aqila Smart. (2010). Bahagia di Usia Nenopause. Yogyakarta : A Plus Book Apreviadizy, P (2014). Perbedaan Stres Ditinjau dari Ibu bekerja dan Ibu Tidak Bekerja: Jurnal Psikologi Tabularasa sebelum dan sesudah intervensi. Hasil uji statistik didapatkan rata-rata 34,70 disimpulkan ada perbedaan signifikan antara fisik sebelum dan sesudah intervensi. Untuk faktor seksual, didapatkan rata-rata sebelum dan sesudah intervensi dapat 24,05 disimpulkan ada perbedaan signifikan antara seksual sebelum dan sesudah intervensi. Sedangkan untuk faktor psikologis didapatkan rata-rata sebelum dan sesudah intervensi 12,66 maka dapat disimpulkan ada perbedaan signifikan antara psikologis sebelum dan sesudah intervensi.

Volume 9, No.1, April 2014: 58-65 UMM

Azwar S. (2013). Sikap Manusia, edisi 2. Pustaka Belajar. Yogyakarta.

Balitbang Kemenkes RI. (2016). Riset Kesehatan Dasar. RISKESDAS: Jakarta Balitbang Kemenkes RI

Bobak, I.M, \& Jensen, M. D. (2012). Perawatan maternitas dan ginekologi. Alih Bahasa. Bandung:YIA-PKP

Bobak, I.M., lowdermilk, D.L, \& Jensen. (2005). Buku ajar Fundamental Keperawatan Konsep, proses dan praktik.ed 4.Jakarta: EGC

Budiman dan Riyanto. A(2013). Kapita Selekta Kuesioner. Jakarta: Salemba Medika

Calapi. F dan Dewi,I (2014). Changes In Physical, Sexual Behavior, And Psychological To Women With Menopause. Kediri:Jurnal STIKes

Chaplin, J P. (2005). Kamus Lengkap Psikologi. Jakarta : Rajawali Pres

Ching-Hui Chen,dkk (2013). Famale Sexual Dysfunction: Definition, Classification, and Debates

Data survei demografi dan Kesehatan Indonesia(SDKI). (2012). Jakarta: Badan Pusat Statistik

Dharma, K.K. (2011). Metodologi Penelitian Keperawatan. Jakarta: Trans Info media 
Dinas Kesehatan Republik Indonesia. (2014). Populasi Penduduk Indonesia: Jakarta

Destia, Hesty. (2015). Hubungan Antara Perubahan Fisik dengan Perubahan psikologis Wanita pada Masa Menopause di Kelurahan Pucang Sawit Kecamatan Jebres. Naskah Publikasi visit 30 Maret 2018

Fraley SS, Altmaier EM. (2002). Corellates of patient satisfaction among menopausal women. $J$ of Clinical Psychology in Medical Settings

Fraley SS, Altmaier. (2002). Corellates of patient satisfaction among menopausal women. $\mathrm{J}$ of Clinical Psychology in Medical Setting

Green, L. W (2011). Health Promotion Planning: An Educational and ecological Approach 4th. ed. New York: McGraw Hill Higher education

Guyton, Arthur (2007). Buku Ajar Fisiologi Kedokteran. Jakarta:EGC

Hastono, S. P (2006). Analisis Data. Jakarta: Fakultas kesehatan Masyarakat Universitas Indonesia

Hawari, D (2013). Seminar Menjelang Menopause Tetap Sehat, aktif Dan Bahagia:Jakarta

Hidayat, A. (2017). Metodologi Penelitian Keperawatan Dan Kesehatan. Jakarta : Salemba Medika

http://ejournal.umm.ac.id/index.php/kepera watan/article/view/2384, 2013

Ismiyati A. (2010). Hubungan tingkat pengetahuan tentang menopause dengan kesiapan menghadapi menopause pada inu premenopause diperumahan Sewon Asri Yogyakarta. Karya Tulis Ilmiah. Universitas Sebelas Maret Surakarta

Jafari, F, Hadizadeh, M, Zabihi, R, Ganji K. (2014). Comparison of Depression, Anxiety, quality of life, Vitality and mental health between premenopausal and postmanopousal women. Climacteric : the journal of the International menopause Society,
Kasdu, Dini. (2002). Kiat sehat dan bahagia diusia menopause, Jakarta: Puspa Swara

Kemenkes no.562 (2007) Tentang Kode etik Penelitian kesehatan

Kementerian Kesehatan RI. (2015). Profil Kesehatan Indonesia 2014. Kementerian Kesehatan Republik Indonesia

Kozier, B Erb, G., Berman, A \& Snyder, S. (2010). Fundamentals of nursing Concepts, Process, and Practice. (8,Ed). California: Addison-Wesley.

Khaadivzade, Najafi \& Ghazanfarfour.(2018). Aromatherapy for Sexual Problems in Menopausal Women: A Systematic Review and Meta-analysis:_Published online 2018 Apr https://doi.org/10.6118/jmm.2018.24.1. 56

Lemeshow,S, David W.H.Jr, (1997). Besar Sampel dalam Penelitian Kesehatan (terjemahan), Gadjahmada University Press, Yogyakarta

Lestari D. (2010). Seluk Beluk Menopause. Jogjakarta: Gerai Ilmu

Manuaba. (2009). Ilmu Kebidanan Penyakit Kandungan Dan keluarga Berencana: Jakarta: EGC

Marmi. (2013). Kesehatan Reproduksi. Yogyakarta: Pustaka Belajar

Melani. (2007). Siapkan Diri Sebelum Menopause Datang. Jakarta: Puspa suara

Mustaqim (2011). Psikologi pendidikan. Jakarta: Rineka Cipta

Mulyani, NS. 2013. Menopause Akhir Siklus Menstruasi pada Wanita di Usia Pertengahan. Yogyakarta: Nuha Medika

Neha M, (2017). Managing Your Own Menopause. International Journal of Current Trends in Science and Technology.

https://doi.org/10.15520/ctst.v7i11.113

Noroozi, E.,Dolatabadi, N. K., Eslami, A.A.h,Hassanzadeh, A., \& Davari, toward menopause phenomenon (2013). Knowledge and attitude 
phenomenon among women aged 40-45 year. Journal of educatication and Health

North American Menopausal society (2016) Symptoms Of Menopause. IQSR, Jurnal of Nurning and health Science (IQSR-JNHS).

Notoatmojo, S. (2012). Ilmu Perilaku Kesehatan. Jakarta : Rineka Cipta

Nursalam. (2017). Metodelogi Penelitian Ilmu Keperawatan. Jakarta: Salemba Medika

Nursanti, I.(2015). Pengembangan Paket Kemilau Senja dan Pengaruhnya Terhadap Pemahaman serta Kemampuan Mengatasi Permasalahan Menopause di Jakarta Timur.

Poverawati, A. (2010). Menopause dan Sindrom Menopause. Yogyakarta: Nuha Medika.

Purwoastuti,E.(2008).Kanker Payudara (Pencegahan dan Deteksi Dini) Yogyakarta:Kanisasus

Rahele Samouei, M. (2018). Psychological experiences of women regarding menopause. Medical Sciences, Isfahan, Iran

Rebecca. (2010). Menopause. Jakarta: Erlangga

Redjeki, S. (2017). Karakteristik dengan Sikap pada Wanita Manopause di Kecamatan Cinere Depok. Seminar Nasional Multi Disiplin Ilmu, Vol. 1.

Richad, Jones-nelso, (2011) . Teori dan Praktik Konseling dan Terapi : Yogyakarta: Pustaka Pelajar
Rose, M. (2012), Peran Religiusitas Mengatasi Kecemasan Masa Menopause. Jurnal Al-Azhar Indonesia Seri Humaniora, Vol . 1, No. 3, Maret 2012

Saragih, F. (2010) . Pengaruh Penyuluhan Terhadap Pengetahuan dan Sikap Ibu Terhadap Makanan Sehat Dan Gizi Seimbang Di Desa Merek Raya Kecamatan Raya Kabupaten Simalungun: FKM USU

Sasrawita, (2017). Hubungan pengetahuan,sikap tentang menopause dengan kesiapan menghadapi menopause. Diakses dari http://doi.org/10.22216/jen.v2.1853

Schilling, L.S.,el. (2009). A New self-report measure of self management of tipe 1 diabetes for adolencents. Nursing Research, 58, 228-236

Sugiyono. (2016). Metode Kuantitatif, Kualitatif dan R\&D (13th ed). Jakarta: EGC

Smeltzer \& Bare. (2008). Textbook of Medical Surgical Nursing Vol.2. Philadelphia: Linppincott William \& Walkins

Tagliaferri, Isaac, M.C, Deby, T. (2007). The New Menopause Book. Jakarta: PT Indeks.

Wawan A \& Dewi, M. (2011). Pengetahuan, Sikap dan Perilaku Manusia. Yogyakarta: Nuha Medika Wawan, A dan Dewi,M.(2010) . Teori dan Pengukuran Pengetahuan, Sikap dan Perilaku manusia. Yogyakarta:Nuha Medika 